\section{Subjective figures: Does brightness enhancement depend upon subjective boundary definition?}

\section{THEODORE E. PARKS \\ University of California, Davis, California 95616}

The ability of certain stimulus patterns to induce figural brightness gradients across what are, in fact, uniform stimulus fields (e.g., Ehrenstein, 1941; Schumann, 1904) has been the subject of extensive theorization since the publication of the pattern depicted in Figure 1a (Kanizsa, 1955). Specifically, many theorists favor a two-stage explanation for such illusory figures in which subjective brightness serves as the sine qua non for their occurrence, that brightness being attributed to simultaneous contrast, assimilation, and dissimilation (see Jory \& Day, 1979) or to the "end-ofline" phenomenon emphasized by other investigators (e.g., Frisby \& Clatworthy, 1975; Kennedy \& Lee, 1976). Given that brightness effects are present, the two-stage model assumes that any figural outlines that might be suggested by such factors as apparent interposition serve merely to modify and sharpen the perimeter of the area of enhanced brightness (e.g., Brigner \& Gallagher, 1974; Frisby \& Clatworthy, 1975; Jory \& Day, 1979; Kennedy, 1978).

Going further, however, it is important to ask whether such implied boundaries are uniquely capable (as compared to physically defined boundaries) of capturing any tendencies towards altered brightness as might be present. If so, it should be possible to show that the substitution of real (for implied) boundaries within a stimulus pattern will serve to reduce the apparent brightness difference between the critical area and the surround. In doing so, however, care must be taken not to interfere with these factors which are thought to induce brightness changes in the first place. Thus, it would be inappropriate to merely outline the triangular area of Figure 1a (see, e.g., Coren \& Theodor, 1975), since such a modification would be expected to interfere with dissimilation and with the end-of-line effects, both of these factors being exemplified in Figure la by the abrupt termination and recommencement of the line segments that form the sides of the partially

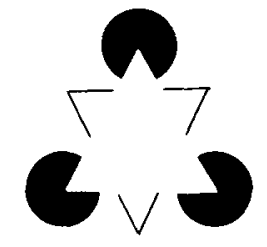

a

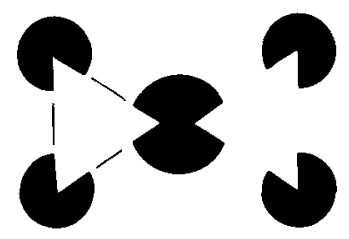

b
Figure 1. (a) The classic subjective-figure stimulus of Kanizsa (1955). (b) The configuration viewed by the present subjects (overall height: $3.8 \mathrm{~cm}$ ).

Copyright 1979 Psychonomic Society, Inc. outlined, apex-down triangle. On the other hand, Kanizsa's figure serves admirably for this purpose if only it is first so modified as to eliminate the effects of dissimilation and line ends in the nonoutlined form (see the right-hand portion of Figure $1 \mathrm{~b}$ ). In this case, of course, any reduction in apparent brightness that results from outlining the critical area (see the left-hand portion of Figure $1 \mathrm{~b}$ ) cannot be attributed to interference with those factors.

When 14 naive subjects were individually shown Figure $1 \mathrm{~b}$ at a distance of $2 \mathrm{~m}, 2$ reported no enhanced brightness for either triangular area. This result is not surprising in that that right-hand portion of Figure $1 \mathrm{~b}$ is a distinctly impoverished version of the classic Kanizsa stimulus. More importantly, when the remaining 12 subjects were asked the relatively nondirective question, "Does one of these triangles seem to be whiter than the other?' all 12 agreed that the nonoutlined triangle was whiter: by exact probability, $p<.01$, two-tailed.

Apparently, the realization of any tendencies towards brightness alteration as happen to be present is enhanced by the simultaneous presence of conditions which lead to implied (as opposed to physically more complete) borders. It is as though the need for perceptual expression of the location of such boundaries might sometimes be satisfied through an alteration in subjective brightness, this process being facilitated by the utilization of whatever tendencies in that direction as are available. If so, such factors as apparent interposition might be causally more primary to the effects observed within patterns such as Figure 1a than the two-stage model would seem to suggest.

\section{REFERENCES}

Brigner, W. L., Gallagher, M. B. Subjective contour: Apparent depth or simultaneous brightness contrast? Perceptual and Motor Skills, 1974, 38, 1047-1053.

Coren, S., \& Theodor, L. H. Subjective contour: The inadequacy of brightness contrast as an explanation. Bulletin of the Psychonomic Society, 1975, 6, 87-89.

Eurenstein, W. Über Abwandlungen der L. Hermannschen Helligkeitserscheinung. Zeitschrift für Psychologie, 1941, 150, 83-91.

Frisby, J. P., \& Clatworthy, J. L. Illusory contours: Curious cases of simultaneous brightness contrast? Perception, 1975, 4, 349-357.

JoRY, M. K., \& DAY, R. H. The relationship between brightness contrast and illusory contours. Perception, 1979, 8, 3-9.

KANizSA G. Margini quasi-percettivi in campi con stimolazione omogenea. Rivista di Psicologia, 1955, 49, 7-30.

KENNEDY, J. M. Illusory contours not due to completion. Perception, 1978, 7, 187-189.

Kennedy, J. M., \& LeE, H. A figure-density hypothesis and illusory contour brightness. Perception, 1976, 5, 387-392.

Schumann, F. Einige Beobachtungen über die Zusammenfassung von Gesichtseindrücken zu Einheiten. Psychologische Studien, $1904,1,1-32$.

(Received for publication October 1, 1979; accepted October 2, 1979.) 